\title{
Hansen's disease with Lucio's phenomenon in a country in the post elimination era: A case report
}

\author{
Santiago Sánchez Pardo*, Luis Daniel Cabeza, Andrés Ochoa Díaz, Claudia Lucia Figueroa, Julio Cesar Mantilla \\ University Hospital of Santander, Industrial University of Santander, Colombia
}

Received: August 2, 2017

Accepted: September 3, 2017

Online Published: September 8, 2017

DOI: $10.5430 /$ crim.v4n4p6

URL: https://doi.org/10.5430/crim.v4n4p6

\begin{abstract}
Leprosy is defined as a chronic granulomatous bacterial infection that affects the skin and peripheral nerves caused by the obligate intracellular bacillus Mycobacterium leprae. According to the 2015 World Health Organization reports, there were 587 prevalent cases and 423 new cases, of the latter 73\% were multibacillary, predominantly in the departments of Santander and Boyacá (Colombia). Lucio's phenomenon was first described in 1852 by Rafael Lucio, in collaboration with Alvarado. The Lucio's phenomenon is relatively rare and none have been reported in Colombia about it, as reference, in South America, Brazil has reported approximately 11 cases since 2000 .
\end{abstract}

We present a rare case of Lucio's phenomenon in a country where leprosy is considered as eradicate which represents a diagnostic challenge, of a disease that continues with increasing incidence rates in a country considered in the post-elimination stage.

Key Words: Hansens' disease, Leprosy, Lucio's phenomenon

\section{INTRODUCTION}

Leprosy is defined as a chronic granulomatous bacterial infection that affects the skin and peripheral nerves caused by the obligate intracellular bacillus Mycobacterium leprae, bound with selective affinity for macrophages and Schwann cells, with marked clinical manifestations in skin and in peripheral nerves, whose histopathological changes depend on the immunological status of the patient at the time of infection and the duration of the infection. ${ }^{[1]}$ At the moment this infection is endemic in more than 15 countries, but about $83 \%$ of the cases are in countries like India, Brazil and Burma. ${ }^{[1]}$ In Colombia, according to data from the Ministry of Health, the goal of elimination was reached in 1997 with a prevalence of 1 case per 10,000 inhabitants. According to the World Health organization (WHO) reports for 2015, there were 587 prevalent cases and 423 new cases, of the latter $73 \%$ were multibacillary, predominantly in the departments of Santander, North Santander and Boyacá (Colombia). ${ }^{[2]}$

The rate of disability grade 2 (advanced or visible) at the time of diagnosis has remained stable in the world, with values from 0.25 to 0.29 per 100,000 inhabitants. According to the WHO in 2015 the proportion of cases with disability at the time of diagnosis showed a great geographical heterogeneity, which ran from zero in the Marshall Islands to $22.8 \%$ in Sudan. In the Region of the Americas, Bolivia reported the lowest proportion, with $3.2 \%$, Venezuela $2.1 \%$, Paraguay $13 \%$ and Colombia the largest with $16.9 \%$, with the result that the situation is further aggravated by the current political situation and migrations. ${ }^{[2,3]}$

The clinical diagnosis is oriented according to three criteria

\footnotetext{
*Correspondence: Santiago Sánchez Pardo; Email: SASANCHEZ21@HOTMAIL.COM; Address: University Hospital of Santander, Industrial University of Santander, Colombia.
} 
established by the OMS:

Hypopigmented or erythematous macules with loss of sensation, thickened peripheral nerves and a rapid spread or positive biopsy for bacillus. ${ }^{[4]}$ Although the gold standard for diagnosis is histopathology, diagnostic tests such as smear microscopy are still considered, because they have a specificity of $100 \%$; the lepromin test that resembles the intradermal reaction like tuberculin (type IV hypersensitivity reaction); and the measurement of Antibody titers against Glycolipid Phenolic 1 (PGL-1), which is not used routinely. ${ }^{[5]}$

Although in 2003 leprosy had been eliminated from 117 countries, it continues to be a public health problem in 17 countries. The treatment is based on a regimen of dapsone, rifampicin and clofazimine. ${ }^{[1,2]}$ Therefore, because it constitutes a disease with potential morbid effects and is in the process of eradication, it is considered relevant by the present paper to describe a case of lepromatous leprosy in an elderly adult that evolved to Lucio's phenomenon in order to expose his diagnosis and the clinical-pathological findings.

\section{Case PResentation}

This is an 81 years old woman who was treated at a third level hospital in the city of Bucaramanga, Colombia, with a presumptive diagnosis of necrotizing vasculitis. The patient reported the onset of symptoms of approximately two months, consisting of the appearance of ecchymosis with posterior necrosis of the fleshy parts of the distal phalanges of the upper limbs (dry gangrene), which appeared after a right hip fracture surgery. At the initial physical examination, a body mass index of $16.4 \mathrm{~kg} / \mathrm{m}^{2}$ was found, additionally with absence of eyebrows, corneal ulceration, conjunctival hyperemia and right lagophthalmos. There were also lesions in the skin, erythematous raised borders and its center light brown, located predominantly on the shoulders and back of the right hand, some of them with central crust. In addition to the above, partial amputations of the distal phalanges from some fingers and from the lower limbs (see Figure 1).

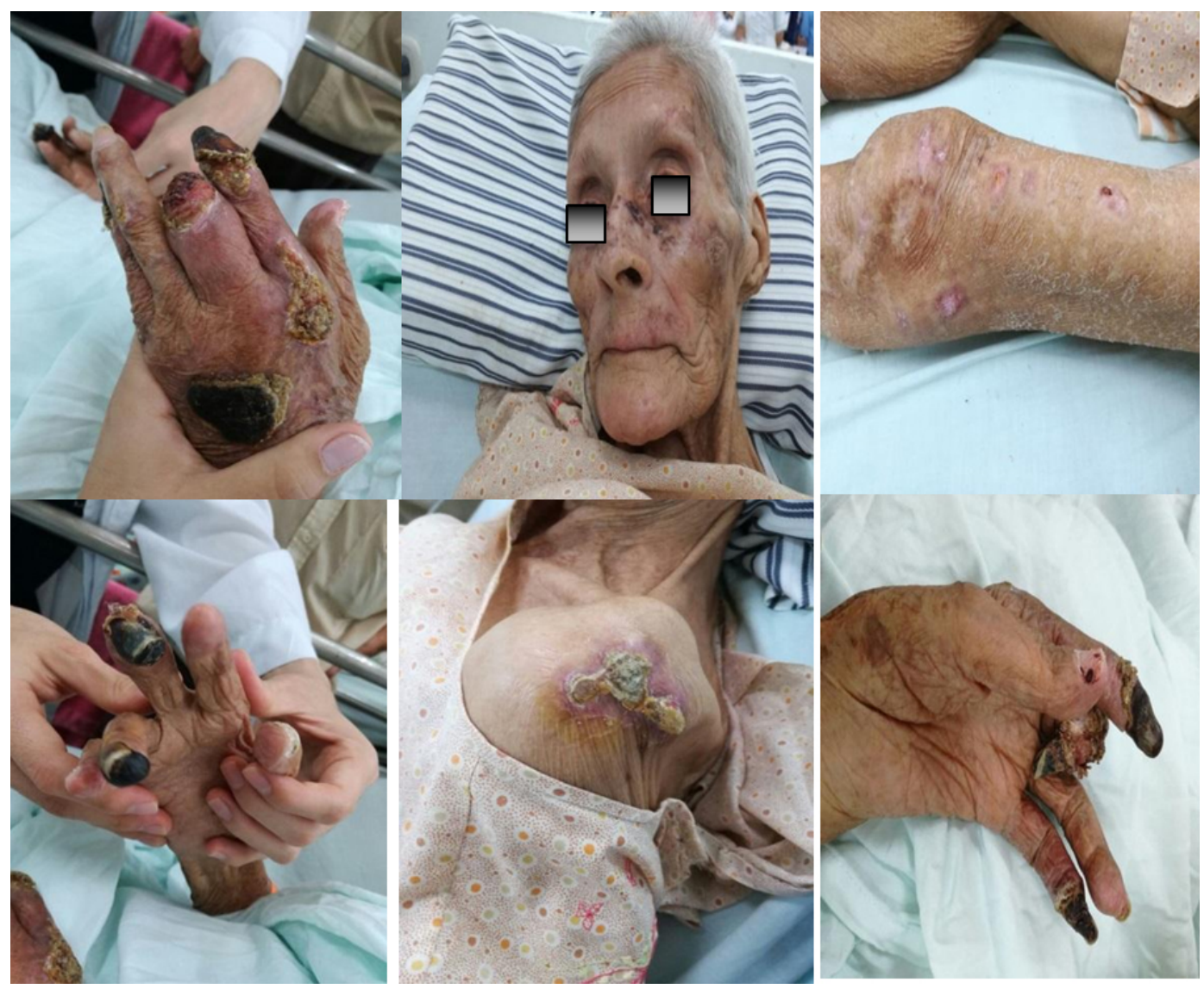

Figure 1. Skin lesions and partial amputations of distal phalanges of upper limbs

Histopathological studies were performed with skin biopsy showing a chronic granulomatous reaction and moderate inflammatory lymphohistiocytic infiltrate and perivascular neu- trophils in the papillary dermis, with mast cells and interstitial plasma cells. Additionally, fibrinoid necrosis of mediumsized blood vessels with endothelial proliferation was ob- 
served, vascular lumen obliteration and some macrophages in the vascular wall. The staining of Ziehl Neelsen demonstrates the presence of bacillus, with which it was considered, a compatible picture with diffuse lepromatous leprosy with necrotizing vasculitis (Lucio's phenomenon) (see Figure 2). A smear microscopy was performed which was negative. A proper therapy was started according to the guidelines of

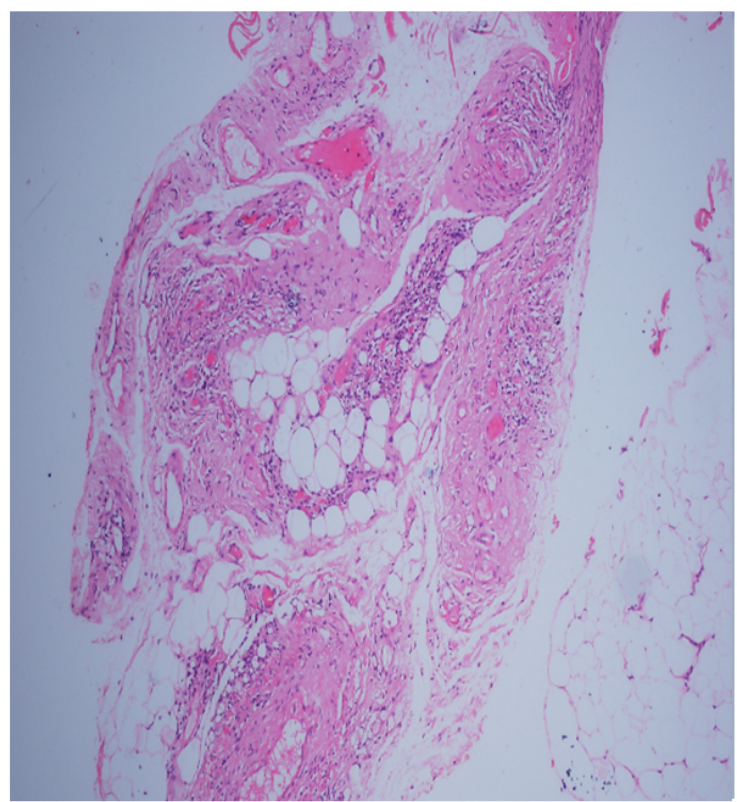

A the national health ministry, with the previously described schedule and with prednisolone at doses of $1 \mathrm{mg} / \mathrm{kg}$ per day as described in the literature for the Lucio's phenomenon, with partial resolution of the skin lesions, but unfortunately the patient finally died three months after hospitalization discharge.

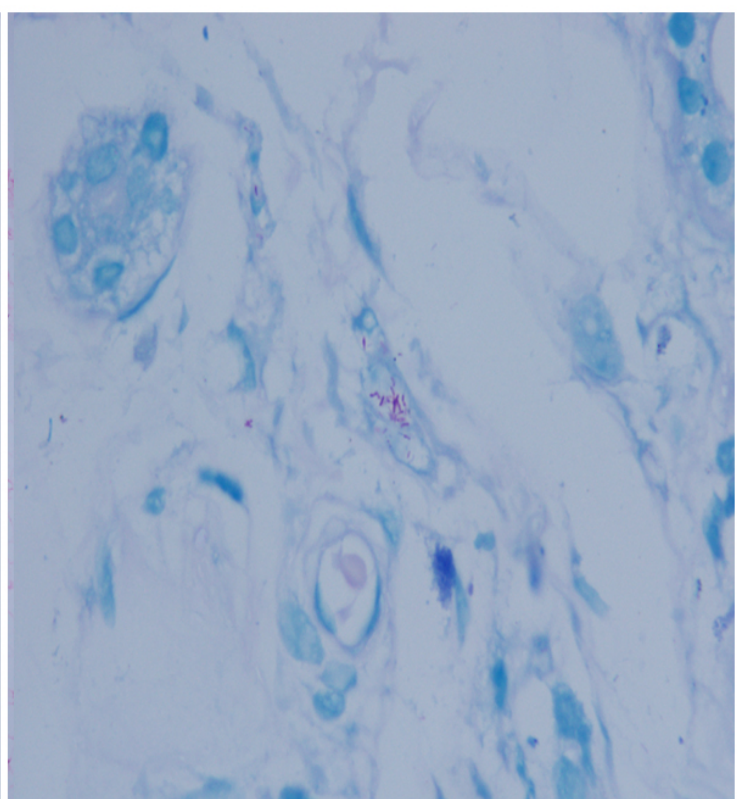

B

Figure 2. Histopathology of skin biopsy

(A) Hematoxylin-Eosin stain with vascular inflammation of the hypodermis with nerve cord compromise. (B) Ziehl-Neelsen staining positive for Bacillus

\section{Discussion}

The clinical manifestations of leprosy are very varied and are classified in different ways; the most well-known one considers two polar forms, one tuberculoid and another lepromatous, among which there are three intermediate forms: dimorfa tuberculoide, dimorfa dimorfa and dimorfa lepromatosa. ${ }^{[5,6]}$

During the chronic evolution of the disease may appear acute inflammatory manifestations called leprotic reactions, which constitute expression of immunoreactivity in which there is compromise of the general condition of the patient with polymorphous skin lesions and severe neural, ocular and visceral involvement that may even lead to death. ${ }^{[4,7]}$ Leprotic reactions may occur before, during, or after appropriate treatment; occur spontaneously or in relation to other infections, stress situations or in situations that alter the patient's immune status. ${ }^{[7]}$

There are three types of reactions that affect $30 \%$ to $50 \%$ of patients with Leprosy: type 1 reaction or reversible reaction; type 2 or Erythema Nodoso Leprosum (ENL) and the third or Lucio's phenomenon that was initially described in 1852 by Rafael Lucio, in collaboration with Alvarado in the work titled "Booklet on the Evil of San Lázaro or Elefanciasis of the Greeks". ${ }^{[7,8]}$ The latter is relatively rare and there are no descriptions in Colombia about it, as a reference in South America, in Brazil approximately 11 cases have been reported since $2000 .^{[6]}$

Lucio's phenomenon is almost exclusively limited to Mexican and Central American patients, although it is rarely reported in South America especially in Colombia. ${ }^{[6]}$ Taking into account that Colombia leprosy was considered eliminated (with a prevalence of less than 1 case per 10,000 inhabitants since 1997), and considering that the country is in a post-elimination phase, it is quite rare to find such cases, as well as the previously presented. ${ }^{[2,9]}$

The Lucio's phenomenon corresponds to a necrotizing vas- 
culitis with microscopic thrombosis and is one of the clinical manifestations of lepromatous leprosy, ${ }^{[8]}$ requires for its diagnosis to document the presence of multibacillary leprosy and the histopathological diagnosis of necrotizing vasculitis in patients without visceral symptoms with painful plaques or nodules that tend to ulcerate, who generally have not received treatment. ${ }^{[6,7,9,10]}$

This usually starts in the feet and advances cephaladically towards the hands, back and face, initially the lesions debut as erythematous macules of different sizes and shapes, which evolve at 24 to 48 hours, and on the third and fourth day to dark purpurical lesions that end in small blisters due to central necrosis, nevertheless, our case presented in the latter phase with necrosis of the fleshy parts of the distal phalanges. ${ }^{[7,8]}$ Usually these patients present alopecia, lagoftalmos, nasal septum destruction or perforation, some of them compatible with the presented case. ${ }^{[6,8]}$

In spite of the above, it is demonstrated that leprosy continues to have a stable incidence with 400 to 500 new cases each year, with which the cohabiting ones become a population of high risk for new infections with percentages near $4 \%$, demonstrated by IgM titers for PGL1 according to RomeroMontoya's work et al. ${ }^{[9]}$ Treatment should be done with the anti-tuberculosis medicines as previously described (dapsone, rifampicin and clofazimine); however, Lucio's phenomenon usually responds to steroids at a dose of $1 \mathrm{mg} / \mathrm{kg} /$ day with a gradual descent pattern, ${ }^{[10]}$ which corresponded to the handling instituting in the exposed case. The syndrome usually occurs in untreated leprosy patients or in patients taking irregular treatment, which agrees with the case presented. It manifests itself 1-3 years after the onset of the disease, however we did not know when primary infection occurred. ${ }^{[8]}$

We present a case of a disease considered as eliminated or little prevalent in this environment with an unusual presentation, which represents a diagnostic challenge and puts forward a disease that continues with stable and possibly increasing incidence rates in a country considered in the post-elimination stage.

\section{ACKNOWLEDGEMENTS}

We thank our patients for allowing us to be our object of study and all the staff of the Hospital that helped in the diagnosis and care of our patient.

\section{CONFLICTS OF INTEREST Disclosure}

The authors have declared no conflicts of interest.

\section{REFERENCES}

[1] Walker LS, Lockwood D. Leprosy. Clinics in Dermatology. 2007; 25 : 165-72. PMid:17350495 https://doi.org/10.1016/j.clinde rmatol.2006.05.012

[2] OMS. Global leprosy update, 2015: time for action, accountability and inclusion. Available from: http://apps.who.int/iris/bi tstream/10665/249601/1/WER9135.pdf?ua=1

[3] Guerrero MI, Muvdi S, León CI. Retardation in the diagnosis of leprosy as a prognostic factor of disability in a cohort of patients in Colombia, 2000-2010. Rev Panam Public Health. 2013; 33(2): 137-43.

[4] Eichelmann K, González SEG, Salas-Alanis JC, et al. Leprosy: Up-to-date. Definition, pathogenesis, classification, diagnosis and treatment. Proceedings Dermosifiliogr. 2013; 104: 554-63. https : //doi.org/10.1016/j.ad.2012.03.003

[5] Silva E, Iyer A, Ura S, et al. Utility of measuring serum levels of anti-PGL-I antibody, neopterin and C-reactive protein in monitoring leprosy patients dur- ing multi-drug treatment and reactions. Trop Med Int Health. 2007; 12: 1450-8. PMid:18076551 https://doi.org/10.1111/j.1365-3156.2007.01951.x
[6] Rocha RH, Emerich PS, Diniz LM, et al. Lucio's phenomenon: Exuberant case report and review of Brazilian cases, An Bras Dermatol. 2016; 91(5 Suppl 1): S60-3. PMid:28300896 https: //doi.org/10.1590/abd1806-4841.20164370

[7] Kamath S, Vaccaro AS, Rea HT, et al. Recognizing and managing the immunologic reactions in leprosy. American Academy of Dermatology. 2014: 795-803. PMid:24767732

[8] Jurado F, Rodriguez O, Novales J, et al. Lucio's leprosy: A clinical and therapeutic challenge. Clinics in Dermatology. 2015; 33: 66-78. PMid:25432812 https://doi.org/10.1016/j.clindermatol .2014 .07 .004

[9] Romero-Montoya M, Beltran-Alzate JC, Cardona-Castro N. Evaluation and Monitoring of Mycobacterium leprae Transmission in Household Contacts of Patients with Hansen's Disease in Colombia. PLoS Negl Trop Dis. 2017; 11(1): e0005325. PMid:28114411 https://doi.org/10.1371/journal.pntd.0005325

[10] Magana M, Fernandez-Diez J, Magana ML. Lucio's phenomenon is a necrotizing panvasculitis: mostly a medium sized granulomatous arteritis. Am J Dermatopathol. 2008; 30: 555-60. PMid:19033928 https://doi.org/10.1097/DAD.0b013e318181270a 